\title{
Restrained concrete shrinkage effect on Concrete Elements strengthened with UHPFRC layers
}

Ourania T. TSIOULOU

Senior Lecturer

University of Brighton

Brighton, UK

o.tsioulou@brighton.ac.uk

Dr Ourania Tsioulou is a Senior Lecturer in Civil Engineering at the University of Brighton in the UK

Cemal AGAOGLU

MEng Civil Engineering student Principal Lecturer

University of Brighton

Brighton, UK c.agaoglu1@uni.brighton.ac.uk

Cemal Agaoglu is a final year MEng Civil Engineering student at the University of Brighton in the UK

\section{Andreas P. LAMPROPOULOS}

University of Brighton

Brighton, UK

a.lampropoulos@brighton.ac.uk

Dr Andreas Lampropoulos is a Principal Lecturer in Civil Engineering at the University of Brighton in the UK

Contact: a.lampropoulos@brighton.ac.uk

\section{Abstract}

Ultra-High Performance Fibre Reinforced Concrete (UHPFRC) is a relatively new material with superior mechanical properties. Recent published studies have confirmed the beneficial contribution of the addition of UHPFRC layers for the structural upgrade of existing Reinforced Concrete (RC) elements.

In case of structures strengthened with additional concrete elements, one of the crucial parameters for the performance and the durability of the strengthened elements is the restrained concrete shrinkage of the new material. The new concrete layer tends to shrink, but due to the connection with the existing structural elements, tensile stresses are induced to the new layers which may lead to the initiation of cracks, while slip is also induced at the old-to-new concrete interfaces. So far, there are not any published studies on the effect of restrained concrete shrinkage on composite UHPFRC-to-normal concrete elements. In this study, experimental work has been conducted on concrete prisms strengthened with UHPFRC layers. Shrinkage strain recordings have been conducted for the composite prisms alongside with relevant recordings for the free shrinkage measurements of standard UHPFRC prisms. The degree of restrained has been calculated and correlated with the induced stresses, and the beneficial contribution of the steel fibres has been highlighted. Flexural tests of the strengthened beams have also been conducted and the results show significant enhancement of the flexural performance of the examined specimens and very good connection between the new UHPFRC layer and the existing concrete substrate.

Keywords: UHPFRC; restrained shrinkage; concrete layers; strengthening.

\section{Introduction}

The majority of the existing structures worldwide and especially in earthquake prone areas need to be strengthened either because they are already damaged or because they have been designed using old code provisions. Strengthening of existing structures with additional Reinforced Concrete (RC) layer or jackets is one of the most commonly used techniques and the effectiveness of this technique is highly affected by the connection between the new and the existing elements [1].
One of the main issues in strengthening applications is the restrained concrete shrinkage of the new concrete layer which may lead to debonding and cracking. The new concrete tends to shrink but the connection with the existing substrate restrains to free shrinkage [2, 3]. This leads to the development of high tensile stresses and potential cracks may appear, while slip may also occur at the interface [2, 3].

In the last few years, the use of novel high performance cementitious materials such as the Ultra High Performance Fibre Reinforced Concrete 
(UHPFRC) have been extensively studied for the structural upgrade of existing structures and it has been found that the use of UHPFRC can considerably increase the stiffness and strength of existing elements $[4,5]$.

However, the effect of restrained concrete shrinkage on RC elements strengthened with UHPFRC has not been sufficiently studied. UHPFRC has a high potential of increased shrinkage strain values which may lead to cracks and durability issues $[6,7]$ therefore it is of high importance to investigate the behaviour of UHPFRC layers under restrained shrinkage.

In this study, concrete prisms strengthened with UHPFRC layers with different percentages of fibres and various thicknesses have been examined. Free and restrained shrinkage strain measurements have been conducted and the tensile stresses due to the restrained shrinkage have been calculated. The flexural performance of the strengthened prisms has also been studied and the effect of the thickness of the additional layer and the steel fibre percentage of the UHPFRC layers have been evaluated.

\section{Experimental procedure}

\subsection{Preparation of UHPFRC and testing}

In the current study four different mixes were examined, one normal conventional concrete (NC) and three Ultra High-Performance Concrete (UHPC) mixes. UHPC mix design was based on a previous study [4] and three different volumetric percentages of steel fibres were examined $(0 \%, 3 \%$ and $5 \%$ ). All concrete mix designs are presented in Table 1.

For the preparation of the UHPC and the Ultra High Performance Fibre Reinforced Concrete (UHPFRC), silica sand with maximum particle size of $500 \mu \mathrm{m}$ was mixed together with i) dry silica fume with retention on $45 \mu \mathrm{m}$ sieve $<1.5 \%$, ii) Ground Granulated Blast Furnace Slag (GGBS), and iii) cement 32.5. Micro silica with fine particles was also used to increase the density of the matrix and to improve the rheological properties of the mix. Low water over cement ratio were used together with polycarboxylate superplasticizer. Steel fibers with
$13 \mathrm{~mm}$ length, diameter $0.16 \mathrm{~mm}$, tensile strength $3000 \mathrm{MPa}$, and modulus of elasticity equal to 200 GPa were used for the UHPFRC.

Table 1. Concrete Mix designs

\begin{tabular}{lllll}
\hline \multirow{2}{*}{ Material } & \multicolumn{4}{l}{ Mix Proportions $\left(\mathrm{kg} / \mathrm{m}^{3}\right)$} \\
\cline { 2 - 5 } & $\mathrm{NC}$ & UHPC & UHPFRC-3 & UHPFRC-5 \\
\hline Cement & 340 & 620 & 620 & 620 \\
Fine aggregates & 1071 & - & - & - \\
Coarse aggregates & 714 & - & - & - \\
GGBS & - & 434 & 434 & 434 \\
Silica fume & - & 140 & 140 & 140 \\
Silica sand & - & 1051 & 1051 & 1051 \\
Superplastisizer & - & 59 & 59 & 59 \\
Water & 205 & 185 & 185 & 185 \\
Steel fibres & - & - & 235.5 & 392.5 \\
& & & $(3 \%$ Vol.) & $(5 \%$ Vol.) \\
\hline
\end{tabular}

Regarding the mixing procedure, all dry ingredients were mixed first. Then, water and superplasticizer were added to the mix and steel fibers were added gradually through sieving.

NC prisms $(100 \mathrm{~mm} \times 100 \mathrm{~mm} \times 500 \mathrm{~mm})$ were initially cast and wet cured in a water tank for 28 days. Then the NC prisms were strengthened with the addition of UHPFRC layers. Three different thickness of UHPFRC layers were examined, $20 \mathrm{~mm}$, $40 \mathrm{~mm}$ and $60 \mathrm{~mm}$.

The surfaces of the initial beams were roughened with a pistol grip needle scaler prior to the application of the UHPFRC layer. Sand patch method was used to quantify the roughness of the surface which was found in the range of $2-3 \mathrm{~mm}$.

In total twelve specimens were tested; ten strengthened and two monolithic ones. From the ten strengthened specimens, two were strengthened with $60 \mathrm{~mm}$ UHPFRC layer with $5 \%$ steel fibres (S-60-5) and the remaining eight were strengthened with UHPFRC layers with $3 \%$ fibres. From the strengthened elements with UHPFRC layers with $3 \%$ fibres, two were strengthened with a layer of $20 \mathrm{~mm}$ thickness (S-20-3), two were strengthened with a layer of $40 \mathrm{~mm}$ thickness (S-403) and four with a $60 \mathrm{~mm}$ layer. In the strengthening layer of two of these specimens with $60 \mathrm{~mm}$ layers, two steel bars with $12 \mathrm{~mm}$ diameter steel grade B500C were also used (SR-60-3). The two monolithic 
specimens had a total cross-sectional height of $160 \mathrm{~mm}$ (M160) to perform comparisons with the respective strengthened/composite prisms.

All the examined specimens are described in Table 2.

Table 2. Description of the examined prisms

\begin{tabular}{|c|c|c|c|c|}
\hline $\begin{array}{l}\text { Specime } \\
\text { n ID }\end{array}$ & $\begin{array}{l}\text { No of } \\
\text { speci } \\
\text { mens }\end{array}$ & $\begin{array}{l}\text { Total } \\
\text { specime } \\
\mathrm{ns}^{\prime} \\
\text { height } \\
(\mathrm{mm})\end{array}$ & $\begin{array}{l}\text { Thicknes } \\
\mathrm{s} \text { of the } \\
\text { layer } \\
(\mathrm{mm})\end{array}$ & $\begin{array}{l}\text { Material of the } \\
\text { layer }\end{array}$ \\
\hline M-160 & 2 & 160 & 0 & N/A \\
\hline S-20-3 & 2 & 120 & 20 & UHPFRC-3 \\
\hline S-40-3 & 2 & 140 & 40 & UHPFRC-3 \\
\hline S-60-3 & 2 & 160 & 60 & UHPFRC-3 \\
\hline S-60-5 & 2 & 160 & 60 & UHPFRC-5 \\
\hline SR-60-3 & 2 & 160 & 60 & $\begin{array}{l}\text { UHPFRC-3 } \\
\text { and } 2 \mathrm{H} 12\end{array}$ \\
\hline
\end{tabular}

The specimens were cured under ambient temperature and humidity for three months after the casting of the layers. Demec points were used to measure the shrinkage strain during the curing time. The Demec points were placed to the top of the surface of the layer, the middle of the height of the layer and the middle of the height of the initial beam as presented in Figure 1. Measurements started 3 days after the casting of the layers.

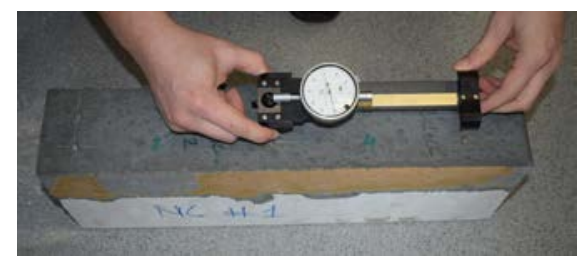

Figure 1. Measurement of the shrinkage strain using Demec points

At the same time, free shrinkage strain measurements were conducted for the examined UHPC and UHPFRC mixes. The setup and the specimen's length proposed by ASTM C 157-04 [8] were followed (Figure 2). Specimens with $285 \mathrm{~mm}$ length and $70 \mathrm{~mm}$ width were used and the thickness and material were selected to be consistent with the thickness of the additional layers of Table 2. Therefore, specimens with $20 \mathrm{~mm}$ (FS-20-3), 40mm (FS-40-3) and $60 \mathrm{~mm}$ (FS-60-3, FS-
60-5, and FSR-60-3) thicknesses were examined (2 specimens for each type).

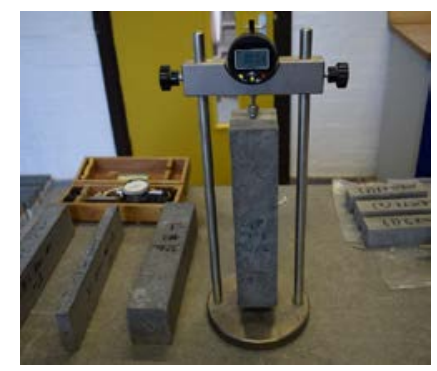

Figure 2. Free shrinkage measurements setup

The results of the free and restrained shrinkage measurements are presented in section 3.2.

\subsection{Shrinkage measurements}

In Figure 3, free shrinkage strain measurements $\left(\varepsilon_{\text {fsh }}\right)$ for $3 \%$ steel fibres mix design with various thicknesses of the layers, with and without additional steel bars, are presented.

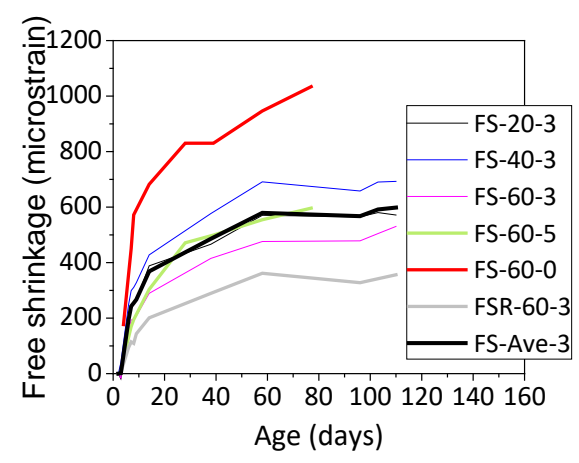

Figure 3. Free shrinkage strain measurements

From the results of Figure 3, it can be observed that the free shrinkage of UHPC without fibres was significantly higher when compared to the respective values of UHPFRC with $3 \%$ and $5 \%$ steel fibres. More specifically, by adding $3 \%$ steel fibres the shrinkage strain was reduced by $45 \%$. Also, the addition of steel rebars to the UHPFRC layer led to further reduction of free shrinkage by $67 \%$ when compared to the values of the specimens without steel fibres.

In Figure 4, the restrained shrinkage distributions along the height of the strengthened prisms with $60 \mathrm{~mm}$ layer, 80 days after the casting of the layers, are presented. 


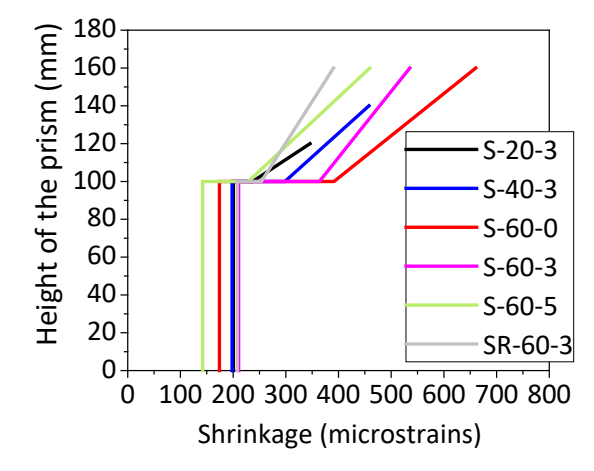

Figure 4. Restrained shrinkage strains along the height of the strengthened specimens

Restrained shrinkage strain $\left(\varepsilon_{\text {ash }}\right)$ measurements were taken at the middle of the height of the strengthening layer and the results are presented in Table 3 together with the free shrinkage strain results $\left(\varepsilon_{\text {fsh }}\right)$.

The values of Table 3 were used for the calculation of the restraint factor $\mathrm{R}$ which is calculated using Equation (1).

$$
\mathrm{R}=\frac{\varepsilon_{\mathrm{fsh}}-\varepsilon_{\mathrm{ash}}}{\varepsilon_{\mathrm{fsh}}}
$$

Table 3. Description of the examined prisms

\begin{tabular}{cccc}
\hline Specimen & $\begin{array}{c}\varepsilon_{\text {fsh }} \\
\text { (microstrains) }\end{array}$ & $\begin{array}{c}\varepsilon_{\text {ash }} \\
\text { (microstrains) }\end{array}$ & $R$ \\
\hline S-20-3 & 573 & 292 & 0.49 \\
S-40-3 & 573 & 378 & 0.34 \\
S-60-0 & 1034 & 526 & 0.49 \\
S-60-3 & 573 & 450 & 0.21 \\
S-60-5 & 596 & 344 & 0.42 \\
SR-60-3 & 573 & 322 & 0.44 \\
\hline
\end{tabular}

To calculate the tensile stresses developed due to the restrained concrete shrinkage, the methodology proposed by Lampropoulos and Dritsos [9] was used.

The tensile stresses $\left(\sigma_{t}\right)$ were calculated using Equations (2-4):

$$
\begin{aligned}
& \sigma_{\mathrm{t}}=\mathrm{E}_{\mathrm{ct}} \cdot\left(\varepsilon_{\mathrm{fsh}}-\varepsilon_{\mathrm{ash}}\right) \\
& \mathrm{E}_{\mathrm{ct}}=\frac{\mathrm{E}_{\mathrm{c}}}{1+\mathrm{x} \cdot \mathrm{C}_{\mathrm{t}}}, \quad 0.774<\mathrm{x}<0.996 \\
& \mathrm{C}_{\mathrm{t}}=2.35 \cdot \frac{\mathrm{t}^{0.6}}{10+\mathrm{t}^{0.6}}
\end{aligned}
$$

where, $E_{c}$ is the concrete modulus of Elasticity; $E_{c t}$ is the reduced value of concrete modulus of Elasticity taking into account the stress relaxation; $t$ is the number of days and $\mathrm{x}$ is taken as 0.8 following the procedure described in [9].

The restrained shrinkage stresses were calculated considering modulus of Elasticity value for UHPFRC equal to $50 \mathrm{GPa}$, following the results of a previous experimental study [10] (Figure 5).



Figure 5. Restrained concrete shrinkage stresses

From the results of Figure 5, it is evident that as the thickness of the layer is reduced, the tensile stresses are increased and therefore the risk of cracking is higher. All the specimens with steel fibres had reduced values of tensile stresses while the specimen without fibres (S-60-0) show very high tensile stresses and increased risk of cracking.

\section{Mechanical testing of the examined specimens}

All the prisms were tested under flexural loading 34 months after the casting of the layers and after the shrinkage strain measurements. Also, standard cubes with $100 \mathrm{~mm}$ side were tested to evaluate the compressive strength of the various mixes. The results of the mechanical testing are presented in this section.

\subsection{Compressive strength}

The average compressive strength of conventional concrete (NC) was found equal to $33 \mathrm{MPa}$. For UHPC the strength was equal to $84 \mathrm{MPa}$, while for $3 \%$ UHPFRC and 5\% UHPFRC the compressive strength was higher and equal to $126 \mathrm{MPa}$ and $147 \mathrm{MPa}$ respectively. From these results it is evident that the addition of steel fibres led to an increment of the compressive strength of UHPC. As the percentage of fibres is increased, the compressive strength is further enhanced. 


\subsection{Flexural and tensile strength}

All the examined prisms were tested under three point bending using deflection control with loading rate $0.21 \mathrm{~mm} / \mathrm{min}$, following BS EN 14651 [11].

The UHPFRC layers were placed on the tensile side of the prisms as presented in Figure 6. For the measurement of the mid-span displacements, two Linear Variable Differential Transformers (LVDTs) were placed at the two sides of the prisms in the middle of the span and the average deflection values were calculated. Also, Digital Image Correlation (DIC) system was used to monitor the concrete-to-UHPFRC interface (Figure 6).

Two specimens were tested for each strengthening type and the average curves are compared with the respective results of the monolithic conventional concrete beams with cross sectional height equal to 160mm (Mono-160).

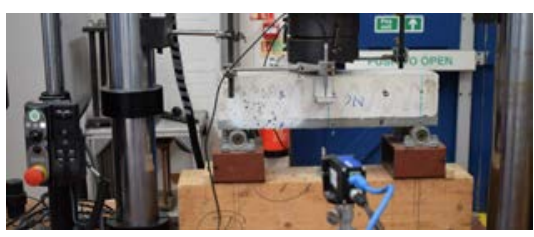

Figure 6. Flexural testing set up

The results of the strengthened specimens with different UHPFRC thicknesses and the same percentage of steel fibres (3\%) are presented in Figure $7 \mathrm{a}$ while in Figure $7 \mathrm{~b}$, the same thickness have been selected $(60 \mathrm{~mm})$ and the steel fibre percentage varies from $0 \%$ to $5 \%$.

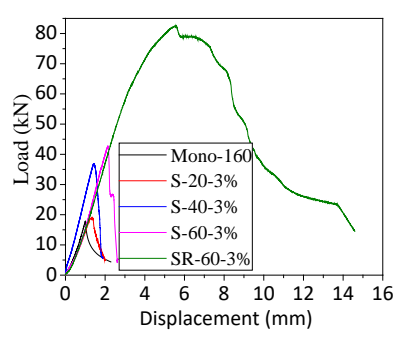

(a)

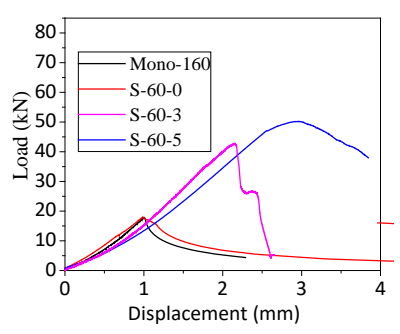

(b)
Figure 7. Load-displacement for monolithic and strengthened specimens a) with 3\% fibres, and $b$ ) with $60 \mathrm{~mm}$ layers and different percentages of steel fibres
From the results of Figure $7 a$ it is evident the behaviour of the conventional concrete monolithic specimen with $160 \mathrm{~mm}$ cross sectional height (Mono-160) show the lowest flexural strength and performed in a very similar way with the specimen strengthened with $20 \mathrm{~mm}$ UHPFRC layer (S-20-3). As the thickness of the layer was increased, the flexural performance was improved as expected. Considerably higher flexural strength was observed for the specimens with UHPFRC layers reinforced with steel bars (SR-60-3).

From the results of Figure $7 \mathrm{~b}$, it is evident that as the fibre percentage is increased, the flexural strength is increased as expected. The specimens with UHPC without fibres (S-60-0) show a behaviour very similar to the behaviour of the monolithic specimen with conventional concrete. Also, it is obvious that the addition of UHPFRC layers considerably enhances the maximum load capacity. For specimens with the same cross section $(160 \mathrm{~mm}$ height), when conventional concrete was replaced by UHPFRC with $3 \%$ and $5 \%$ fibre percentage, the maximum load was increased by $139.51 \%$ and $181.82 \%$ respectively. The specimens with UHPC layer without fibres had a maximum load very close to the ones with conventional concrete.

The concrete-to-UHPFRC interface behaviour was also monitored during the tests and it was found that perfect bond was achieved in all the examined specimens. High shear strain and cracks at the level of the interface only occurred after the failure of the specimens with steel bars (SR-60-3) when cracks propagated from the UHPFRC layer to the interface.

Typical DIC results for specimens S-20-3, S-40-3, and SR-60-3 at a loading stage near the failure, are presented in Figure $8 \mathrm{a}, \mathrm{b}$, and $\mathrm{c}$ respectively.

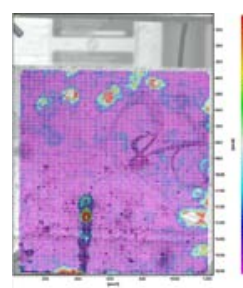

(a)

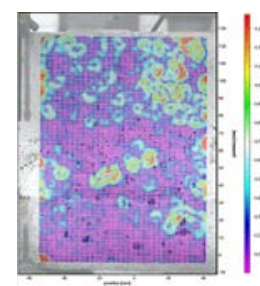

(b)

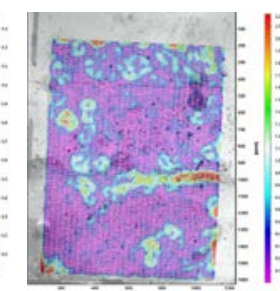

(c)
Figure 8. Typical DIC results for a) S-20-3, b) S-403 , and c) SR-60-3 
From the results of Figure $8 \mathrm{a}$, and $8 \mathrm{~b}$ it is evident that there is not any shear strain concentration at the interface of these specimens and therefore perfect connection was achieved. The initiation of a crack near the interface of specimen SR-60-3 can be seen in Figure 8c. This occurred after the failure of the specimen when cracks propagated from the UHPFRC layer to the interface.

\section{Conclusions}

This study was focused on the shrinkage strain and flexural performance of concrete prisms strengthened with additional UHPFRC layers. Various thicknesses of UHPFRC layers and different percentages of steel fibres were used while in some of the examined specimens steel bars were also used in the UHPFRC layers. The main findings of this study are summarised below:

- The free shrinkage strain of UHPC without fibres was significantly higher when compared to the respective values of UHPFRC with $3 \%$ and $5 \%$ steel fibres. The addition of steel rebars in the UHPFRC led to further reduction of free shrinkage strain.

- In case of strengthened elements, as the layers' thickness was reduced, the tensile stresses were increased, and the risk of cracking was higher.

- The additional UHPC layers without steel fibres show very high tensile stresses and increased risk of cracking, while the tensile stresses were considerably reduced for UHPFRC layers.

- From the flexural test results, it was observed that as the thickness of the UHPFRC layer and as the fibre percentage were increased, the flexural performance was improved, as expected.

- Considerably higher flexural strength was achieved for specimens with UHPFRC layers reinforced with steel bars.

- Very good bond between the UHPFRC and the existing conventional concrete was observed for all the examined specimens.

\section{References}

[1] O. Tsioulou, A. Lampropoulos and S. Dritsos, "Experimental investigation of interface behaviour of RC beams strengthened with concrete layers," Construction and Building Materials, vol. 40, pp 50-59, 2012.
[2] A. Lampropoulos and S. Dritsos, "Concrete shrinkage effect on columns strengthened with concrete jackets" Structural Engineering International, vol. 20(3), pp 234 - 239, 2010.

[3] A. Lampropoulos, O. Tsioulou, and S. Dritsos, "Biaxial stress due to shrinkage in concrete jackets of strengthened columns" ACl Materials Journal, vol. 109(3), pp 331-340, 2012.

[4] S. Paschalis, A. Lampropoulos and O. Tsioulou, "Experimental and numerical study of the performance of ultra high performance fiber reinforced concrete for the flexural strengthening of full scale reinforced concrete members," Construction and Building Materials, vol. 186, pp $351-366,2018$.

[5] A. Lampropoulos, S. Paschalis, O. Tsioulou and S. Dritsos., "Strengthening of reinforced concrete beams using ultra high performance fibers reinforced concrete(UHPFRC)," Engineering Structures, vol. 106, pp 370-384, 2015.

[6] D. Yoo, S. Kim and M. Kim, "Comparative shrinkage behavior of ultra-high-performance fiber reinforced concrete under ambient and heat curing conditions," Construction and Building Materials, vol. 162, pp 406 - 419, 2017.

[7] O. Oladiran, Assessment of restrained shrinkage cracking of concrete through elliptical rings. Brunel University Department of Civil Engineering, 2014

[8] ASTM C 157-04, Standard Test Method for Length Change of Hardened Hydraulic Cement, Mortar, and Concrete. West Conshohocken: American Society for Testing and Materials, 2003.

[9] A. Lampropoulos and S. Dritsos, "Concrete shrinkage effect on columns strengthened with concrete jackets," Structural Engineering International, vol. 20, pp 234-239, 2010.

[10] A. Lampropoulos and S. Paschalis, "Fiber content and curing time effect on the tensile characteristics of ultra high performance fiber reinforced concrete," Structural Concrete, vol. 18(4), pp 577-588, 2017.

[11] BRITISH STANDARD INSTITUTION, BS EN 14651 Test methods for metallic fibered concrete- Measuring the flexural strength (limit of proportionality (LOP), residual). London: BSI, 2005. 